\section{Barrier protection}

Omnia barrier products enable the clinician to keep touchable surfaces around the patient and operator clean and safe, and help to maintain the life of delicate surfaces and equipment, according to Minerva Dental. The range includes barrier protection products for x-ray units, handpieces, airlines and tubing, digital imaging sensors, light curing units and telephones.

Reader response number 54

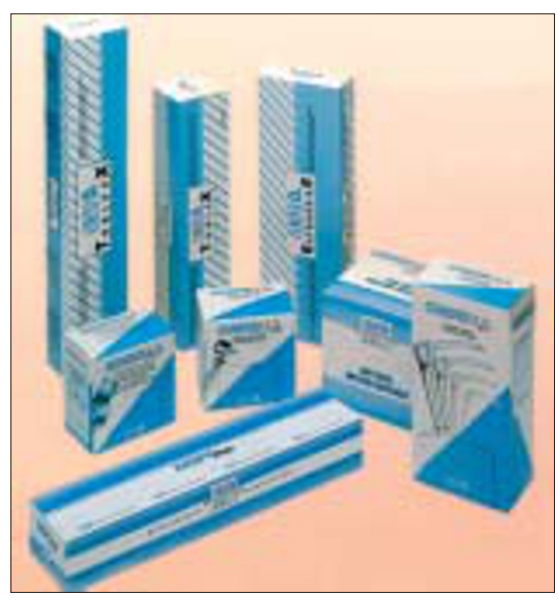

\section{Syringe sleeve}

The Syringe Sleeve, from Professional Dental Supplies, can be used as disposable barrier protection for three-way syringes and to successfully cover and protect equipment including hand pieces, saliva ejectors, cavitrons, jet polishers and HVE valves.

It is designed to minimise the potential for cross contamination within the practice by reducing splattering, and

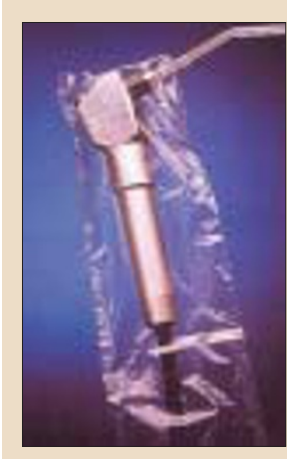
consequently the spread of infectious materials.

The Syringe Sleeve can be used by being slipped over the required equipment and disposed of after use. Reader response number 56

\title{
Caring cleansing
}

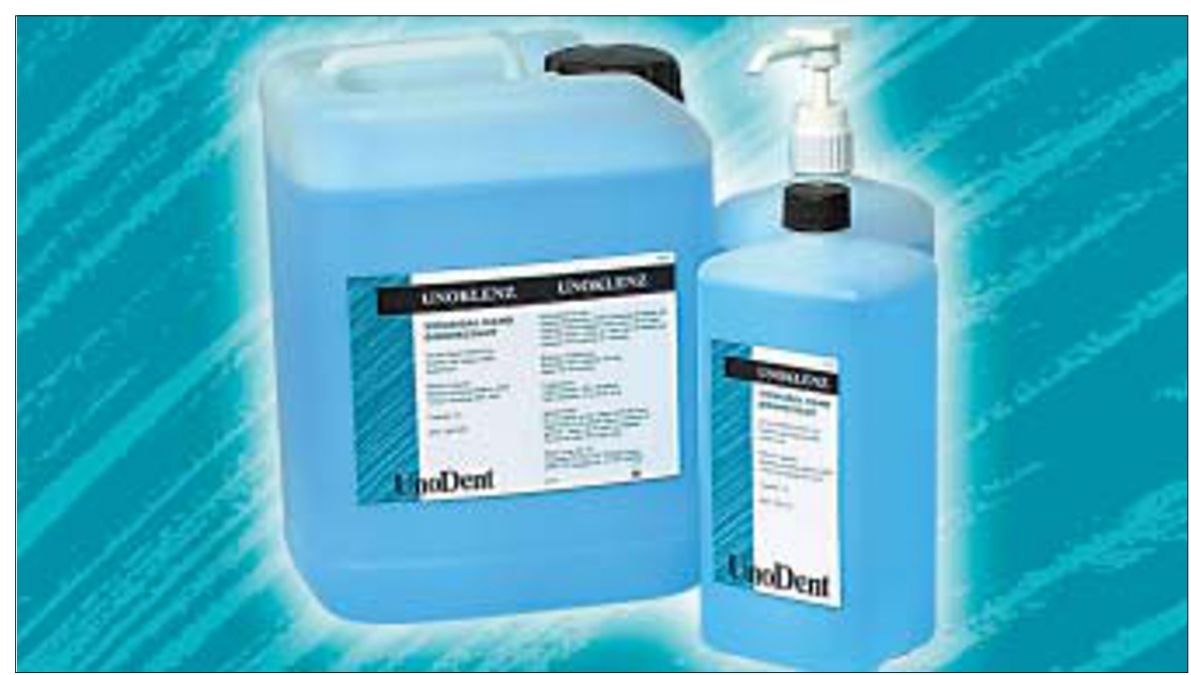

Unoklenz from UnoDent is a hand-disinfectant that will ensure hands remain clean but well cared for. According to the manufacturer it is an effective bactericide, fungicide and has anti-viral properties (including Hepatitis B and HIV).

It also contains skin care additives to

\section{New additions}

Sirona has added two new additions to its hygiene systems range.

The Siromini B is a high-speed sterilizer designed to handle difficult sterilization loads, for instance, hollow objects such as dental handpieces.

The Siromini B offers up to four prevacuum phases. The small-sized chamber permits very short cycle times, while the four standard programs and a variety of other options can be selected at the touch of a button.

Also available is Siroclean, a compact system designed for the machine-based cleaning and the thermo-chemical disinfection of dental instruments, which can minimize the risk of contamination caused by sharp-pointed instruments.

Four different programmes cover a broad spectrum of applications from simple cleaning to full-scale disinfection and also prior to sterilization.

Reader response number 57 ensure hands remain soft and supple and it leaves no residue. The product can be supplied in either a hand pump or elbow dispenser, both of which dispense $3 \mathrm{ml}$ doses. UnoKlenz is available from The Dental Directory.

Reader response number 55

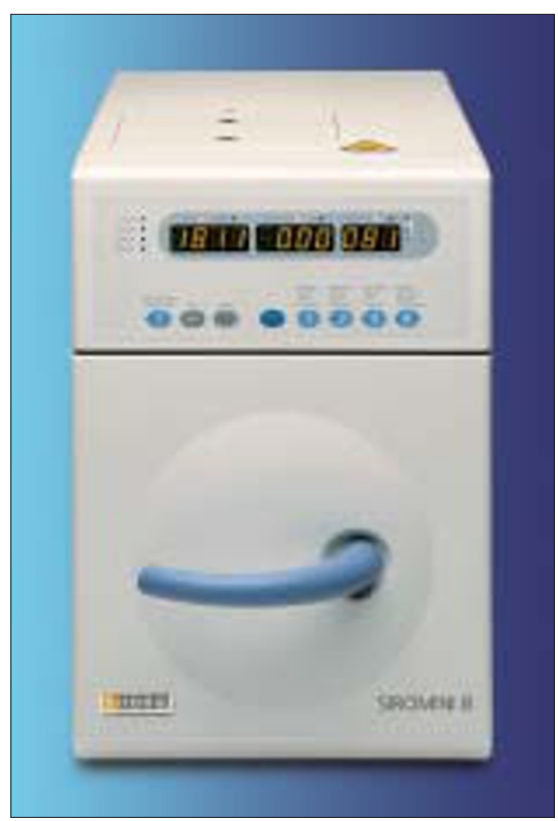




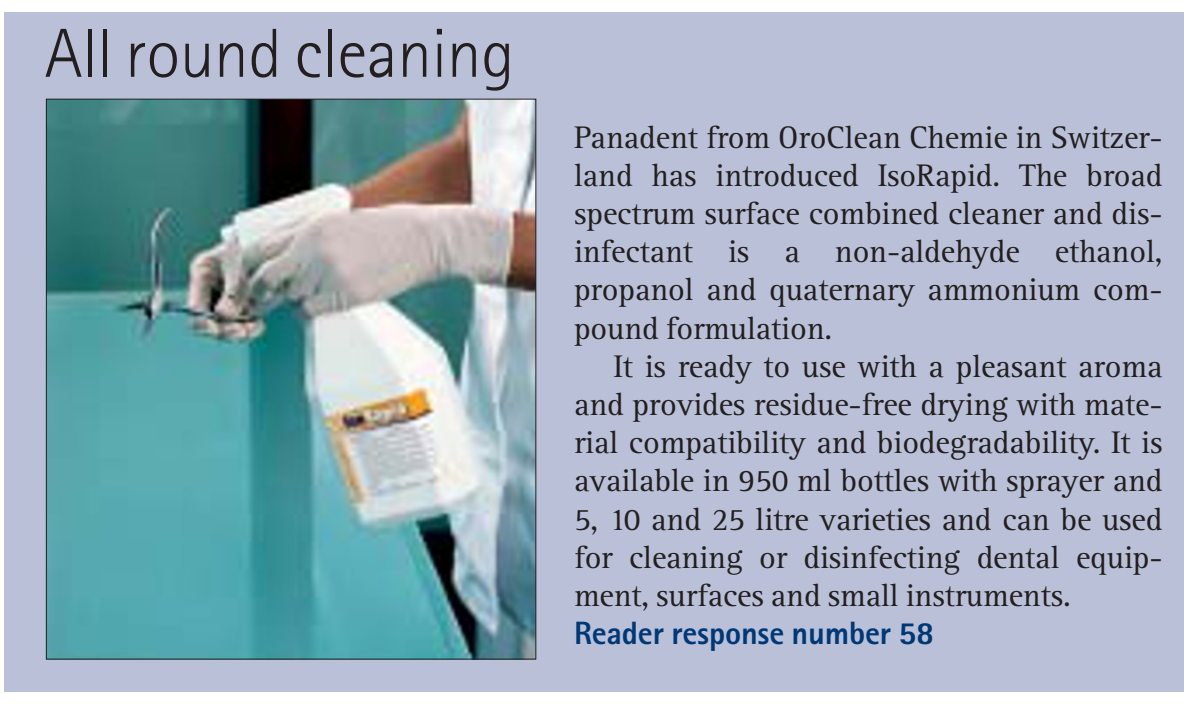

\section{Cleaner air}

MedicCleanAir is the new addition to Henry Schein's range of dental equipment. It has been designed to eliminate indoor airborne pollution in the dental practice. It removes all regular airbourne pollution, including gases, chemical components, airborne particles, bacteria and viruses.

The company claims that airborne infectious agents are reduced by more than 80 per cent in a high care environment and that there are no side effects, such as the creation of ozone or the breeding of microorganisms. With four levels of air cleaning capacity it enables rooms to be cleaned in a brief time period. It is technically capable of 24 hours a day continuous cleaning, using mechanical filters to ensure safety in operation.

Reader response number 59

\section{Wipe it away}

New Alkapharm Grande Wipes are the latest addition to Alkapharm's Wipes range. As dual action disinfecting and cleaning wipes for the prevention of cross contamination, they have been specifically manufactured to clean all hard surfaces, furniture, equipment and devices within the dental surgical environment.

According to the company, the cleansing agents within the wipes can protect against bacteria, fungi and viruses including HIV, HBV, rotavirus and poliovirus and contain no aldehydes, chlorine or phenols. They can also mask all other unpleasant odours. The product comes in tubs of 200 wipes (200 mm x $220 \mathrm{~mm}$ ). Reader response number 60

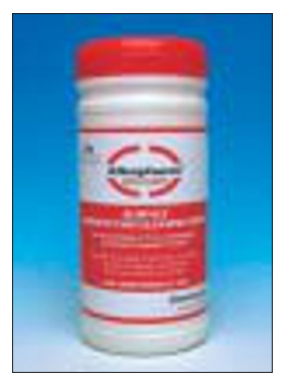

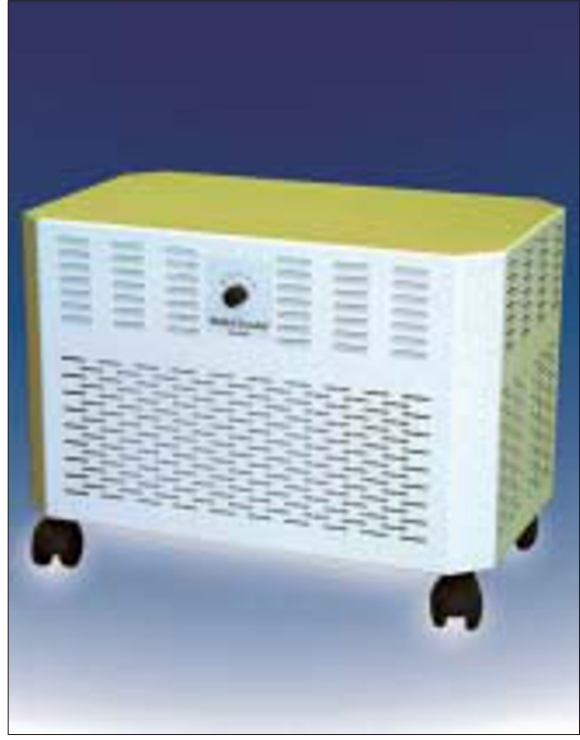

\section{Disposable solutions}

A range of single unit doses and disposable equipment has been designed by Dentsply. The range includes Sani-Tip Disposable Syringe tips which are 3-in1 , clear plastic air and water syringe tips featuring a central water channel encircled by six air channels.

The Disposa-Shield is designed to fit over surfaces to prevent cross contamination and is manufactured in a variety of sizes to fit switches to headrests. Delton single cartridges provide protection against caries and their low viscosity ensures the material is able to flow freely into fissures and interdental spaces. Reader response number 61 